TẠP CHÍ KHOA HỌC ĐẠI HỌC TÂN TRÀO

ISSN: $2354-1431$

http://tckh.daihoctantrao.edu.vn/

\title{
Phát triển văn hóa chất lượng và hệ thống đảm bảo chất lượng bên trong Trường Đại học Tân Trào
}

\author{
Trần Minh Tú ${ }^{a^{*}}$ \\ ${ }^{a}$ Trưòng Đại học Tân Trào \\ *Email: tu.pktdaihoctantrao@gmail.com
}

\section{Thông tin bài viết}

Ngày nhận bài:

26/01/2018

Ngày duyệt đăng:

$10 / 3 / 2018$

\section{Tù khoá:}

Văn hóa chất luợng;đảm bảo chất luợn;nâng cao chất lượng giáo dục.

\section{Tóm tắt}

Phát triển văn hóa chất lượng và chuẩn hóa hệ thống đảm bảo chất lượng bên trong là yêu cầu tất yếu trong chiến lược phát triển của trường Đại học Tân Trào. Công tác đảm bảo chất lượng bên trong đóng vai trò quan trọng trong việc nâng cao chất lượng đào tạo, nghiên cứu khoa học và dịch vụ cộng đồng. Đẩy mạnh các hoạt động đảm bảo chất lượng là nhiệm vụ xuyên suốt của nhà trường nhằm đáp ứng yêu cầu về nguồn nhân lực cho sự phát triển của xã hội và của địa phương, phù hợp với xu thế tất yếu của thời đại - xu hướng quốc tế hóa, toàn cầu hóa của giáo dục đại học Việt Nam.

\section{1. Đặt vấn đề}

Trong xu thế phát triển chung của giáo dục đại học ở khu vực và thế giới hiện nay, giáo dục đại học Việt Nam đang đổi mới hết sức mạnh mẽ và đạt được nhiều thành tựu nhất định. Tuy nhiên, để có thể được công nhận ở khu vực và quốc tế, giáo dục đại học Việt Nam cần có những chiến lược và giải pháp phát triển mạnh mẽ và toàn diện hơn về hệ thống giáo dục đại học nói chung và hệ thống đảm bảo chất lượng nói riêng, trong đó xây dựng và phát triển văn hóa chất lượng trong tổ chức là điều kiện đảm bảo để xây dựng thành công hệ thống đảm bảo chất lượng trong trường đại học, qua đó để nâng cao chất lượng giáo dục đại học.

Khái niệm "văn hóa chất lượng" được nhắc đến tại một số trường đại học ở Hoa Kỳ từ những năm đầu của thế kỷ 20. Cho đến nay, mặc dù khái niệm văn hóa chất lượng không còn xa lạ, mới mẻ đối với các nhà làm công tác giáo dục, nhưng thật khó để tìm ra được một định nghĩa thống nhất về khái niệm. Có rất nhiều quan điểm, ý kiến nêu lên những khía cạnh khác nhau, đa dạng và đa chiều trong nội hàm của khái niệm. Theo EUA (2006) thì "Văn hóa chất lượng là một loại văn hóa tổ chức trong đó việc nâng cao chất lượng được xem là một việc làm thường xuyên bao gồm 2 yếu tố riêng biệt, đó là yếu tố văn hóa/tâm lý và yếu tố quản lý..." [8]. Về khái niệm "Đảm bảo chất lượng bên trong", theo Intemational institute for Educational Plannir "Đảm bảo chất lượng bên trong là hệ thống các chính sách và cơ chế để vận hành một trường đại học hoặc một chương trình giáo dục nhằm đảm bảo nhà trường hoặc chương trình giáo dục được đáp ứng đầy đủ các mục tiêu và chuẩn mực được áp dụng cho trường đại học hoặc chương trình giáo dục đó" [7].

Văn hóa chất lượng được trường Đại học Tân Trào tiếp cận theo quan điểm "là hệ thống các giá trị, chuẩn mực và thói quen làm việc có chất lượng đã định hình của mọi thành viên trong đơn vị nhằm thực hiện công việc được giao một cách tốt nhất". Theo quan điểm này, văn hóa chất lượng phải được thấm nhuần trong những quy tắc hành động, những thói quen thực hiện tốt nhiệm vụ được giao của tất cả đội ngũ cán bộ, công chức, viên chức và người học của trường nhằm tạo ra cho xã hội những sản phẩm đào tạo và nghiên cứu khoa học đáp ứng cao nhất yêu cầu của người sử dụng.

Văn hóa chất lượng và hệ thống đảm bảo chất lượng bên trong có quan hệ hữu cơ và phụ thuộc lẫn 
nhau, cơ cấu đảm bảo chất lượng bên trong sẽ không tạo được chất lượng bền vững nếu không có văn hóa chất lượng, nhưng cơ cấu đảm bảo chất lượng có thể tạo ra các thói quen, sự mong đợi và giá trị chung mà mọi người cùng chia sẻ [1]. Văn hóa chất lượng chính là một trong những thành tố then chốt của hệ thống đảm bảo chất lượng bên trong tổ chức và văn hóa chất lượng quyết định tính bền vững của hoạt động đảm bảo chất lượng [3]. Để đáp ứng yêu cầu về chất lượng giáo dục, sự cần thiết của các cơ sở giáo dục đại học là phải xây dựng, phát triển văn hóa chất lượng và hệ thống đảm bảo chất lượng bên trong một cách bền vững.

Trường Đại học Tân Trào là cơ sở đào tạo đại học thuộc hệ thống giáo dục quốc dân, là đơn vị sự nghiệp công lập trực thuộc Ủy ban nhân dân tỉnh Tuyên Quang, chịu sự quản lý nhà nước về giáo dục của Bộ Giáo dục và Đào tạo. Với chức năng là thực hiện việc đào tạo, bồi dưỡng, nghiên cứu khoa học, triển khai ứng dụng khoa học, công nghệ và làm các dịch vụ đào tạo theo quy định của pháp luật, hợp tác quốc tế. Ngay từ khi mới thành lập, trường đã sớm xây dựng và công bố sứ mạng của trường "Trường Đại học Tân Trào là cơ sở đào tạo đại học, sau đại học, nghiên cứu khoa học, ứng dụng và chuyển giao công nghệ trong các lĩnh vực giáo dục, kinh tế, văn hóa, khoa học kỹ thuật; đóng vai trò nòng cốt trong hệ thống các trường đào tạo chuyên nghiệp của tỉnh Tuyên Quang; sẵn sàng hội nhập quốc tế”. Trường phấn đấu trở thành một trong những cơ sở giáo dục đại học có uy tín và chất lượng, góp phần đào tạo nguồn nhân lực chất lượng cao phục vụ sự phát triển kinh tế - xã hội của tỉnh Tuyên Quang và các tỉnh lân cận trong khu vực.

Chất lượng đào tạo luôn luôn là vấn đề được trường quan tâm hàng đầu. Trong khi, toàn cầu hóa là một xu thế tất yếu của thời đại, buộc các trường đại học phải không ngừng vươn lên, đổi mới có mục đích chương trình đào tạo, phương pháp giảng dạy theo hướng tiên tiến của thế giới. Hiện nay, trường đã và đang tích cực xây dựng, rà soát, bổ sung chương trình đào tạo với mục tiêu cụ thể, rõ ràng. Đồng thời, trường chuyển đổi hình thức đào tạo từ niên chế sang học chế tín chỉ từ năm học 2014 - 2015 nhằm tạo điều kiện thuận lợi cho người học, rèn luyện khả năng tự học. Trường đã tích cực đa dạng hóa các loại hình đào tạo nhằm đáp ứng nhu cầu học tập của người học, đáp ứng nhu cầu sử dụng nguồn nhân lực của ngành và của địa phương.
Việc phát triển văn hóa chất lượng và hệ thống đảm bảo chất lượng bên trong là chủ trương nhất quán và là nội dung ưu tiên của nhà trường. Thực tiễn cho thấy đây là công việc khó khăn và đầy thách thức nhưng kinh nghiệm cũng chỉ ra chìa khóa thành công. Đó chính là sự thay đổi nhận thức, một tầm nhìn dài hạn và sự quyết tâm của lãnh đạo, một cơ cấu tổ chức và cơ chế vận hành mang tính hỗ trợ, nhất là sự hợp tác hiệp lực tự giác tất cả các bên liên quan cùng sự đầu tư nguồn lực thích đáng.

\section{Nội dung}

\subsection{Phát triển văn hóa chất lự̛ng Truờng Đại} học Tân Trào

Phát huy vai trò của mình trong hệ thống giáo dục đại học và trong khu vực cũng như cả nước, trường Đại học Tân Trào đã xác định: Chất lượng là sự ưu tiên, là nhiệm vụ quan trọng và là mối quan tâm hàng đầu trong chiến lược phát triển nhà trường; chất lượng được ưu tiên lồng ghép và xuyên suốt trong mọi hoạt động; chất lượng là sự cải tiến thường xuyên, liên tục, khuyến khích sự sáng tạo trong cơ chế, bộ máy hoạt động của đơn vị để đạt được những tiêu chí chất lượng; ưu tiên đánh giá chất lượng chương trình đào tạo, vì hoạt động này sẽ góp phần đánh giá chính xác chất lượng của cơ sở giáo dục.

Chất lượng được duy trì và củng cố bởi văn hóa chất lượng, thông qua hệ thống quản lý và các giá trị được khẳng định, trở thành một trong những yếu tố hình thành nên truyền thống của nhà trường. Hoạt động xây dựng và phát triển văn hóa chất lượng đã được thể hiện trong nghị quyết của Đảng ủy và kế hoạch chiến lược của trường Đại học Tân Trào. Thực hiện mục tiêu đề ra, nhà trường đã ban hành hệ thống văn bản hướng dẫn cụ thể cho các hoạt động xây dựng và phát triển văn hóa chất lượng trong các đơn vị trong toàn trường. Tăng cường sự lãnh đạo của Đảng, sự tham gia của các tổ chức đoàn thể vào quá trình ra các quyết định liên quan và thực hiện văn hóa chất lượng; Tuyên truyền tới tất cả cán bộ nhân viên, người học để hiểu, nắm chắc chiến lược của đơn vị, giá trị, ý nghĩa và thói quen làm việc có chất lượng và lợi ích của việc thực hiện các hoạt động đảm bảo chất lượng của đơn vị, đưa nội dung phát triển văn hóa chất lượng vào kế hoạch chiến lược trung hạn, dài hạn, hàng năm của nhà trường. Xây dựng, phát triển và vận hành hệ thống đảm bảo chất lượng trong nhà trường, các quy trình đảm bảo chất lượng trong từng lĩnh vực hoạt 
động của đơn vị, ban hành các văn bản quản lý về đảm bảo chất lượng, thực hiện các hoạt động đánh giá, kiểm định chất lượng giáo dục. Trong mỗi năm học, lựa chọn nội dung ưu tiên phát triển đối với từng tiêu chí, giao cho đơn vị chuyên trách công tác đảm bảo chất lượng lập kế hoạch, lộ trình thực hiện, theo dõi, đánh giá chung tiến độ triển khai. Kiểm tra và giám sát để mọi hoạt động hướng tới đạt được chất lượng cam kết, đảm bảo tất cả các nguồn nhân lực trong đơn vị phát huy hết năng lực và được cung cấp đủ các điều kiện để có thể phát huy tối đa năng lực cá nhân, các cá nhân và đơn vị thấm nhuần về vai trò của mình trong lộ trình xây dựng và phát triển văn hóa chất lượng. Từng thành viên trong đơn vị được phân cấp trách nhiệm rõ ràng, tạo dựng được nhận thức về trách nhiệm cá nhân và trách nhiệm chung trong đơn vị, được đào tạo, bồi dưỡng để phát triển năng lực chuyên môn và động cơ làm việc đúng đắn. Xây dựng các tiêu chí đánh giá việc thực hiện xây dựng và phát triển văn hóa chất lượng cúa các tổ chức và cá nhân. Định kỳ hàng năm tổ chức đánh giá cấp trường về kết quả đạt được.

\subsubsection{Mô hìn phát triển văn hóa chất luợng của} truò̀ng Đại học Tân Trào

Trên cơ sở tham khảo các mô hình về văn hóa chất lượng trong và ngoài nước , trường Đại học Tân Trào đã chọn "Mô hình văn hóa chất lượng cơ sở giáo dục đại học" để làm mô hình phát triển văn hóa chất lượng cho nhà trường (Hình 1 ). Mô hình này dựa trên sự tích hợp các quan niệm về văn hóa chất lượng, các yêu cầu từ bộ tiêu chuẩn kiểm định chất lượng trường dại học của $\mathrm{BGD \& ĐT} \mathrm{và} \mathrm{các} \mathrm{bộ} \mathrm{tiêu}$ chuẩn kiểm định chất lượng cúa các tổ chức $\mathrm{AUN}$, ABET. Mô hình gồm 5 thành tố đặc trưng cho các yếu tố của môi trường tổ chức giúp văn hóa chất lượng phát triển.

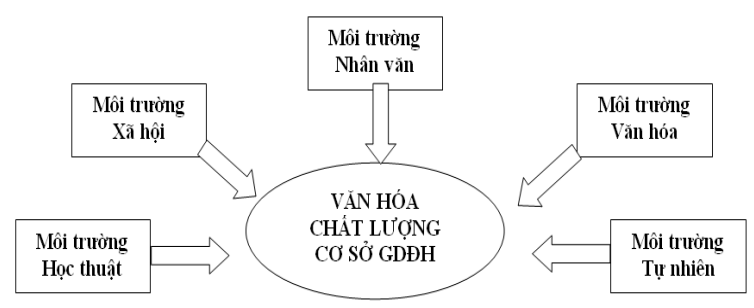

Hình 1: Mô hình phát triển văn hóa chất luợng của trưòng Đại học Tân Trào

Môi trường học thuật: Là môitrường trong đó diễn racác hoạt động học thuật: các hoạt động dạy và học, nghiên cứu, trao đổi theo những quan điểm và phương pháp giáo dục, nghiên cứu tiên tiến, tôn trọng các tiêu chuẩn đạo đức trong chuyên môn.

Môi trường xã hội: Là môi trường trong đó các mối quan hệ xã hội, bao gồm khung tổ chức và những chủ trương, chính sách, quy định giúp cho hoạt động của cơ sở GDĐH và hành vi của các thành viên được xác lập đầy đủ, góp phần tạo nên sức mạnh của cơ sở GDĐH.

Môi truờng nhân văn: Là môi trường trong đó quyền và nghĩa vụ của các thành viên và các bên liên quan của cơ sở GDĐH.được xác lập tường minh và được tuân thủ, góp phần nâng cao chất lượng hoạt động của cơ sở GDĐH.

Môi trường văn hóa: Là môi trường được xác lập hệ thống các chuẩn mực, giá trị, niềm tin, quy tắc ứng xử được xem là tốt đẹp và được các thành viên trong cơ sở GDĐH đồng thuận và tự giác thực hiện.

Môi trường tụ nhiên: Là môi trường cảnh quan, cơ sở vật chất góp phần đảm bảo và nâng cao chất lượng các hoạt động của cơ sở GDĐH.

\subsubsection{Kế hoạch phát triển văn hóa chất luợng} truờng Đại học Tân Trào

\subsubsection{Phát triển môi truờng học thuật}

- Định kỳ bổ sung, điều chỉnh các chương trình đào tạo trên cơ sở tham khảo các chương trình tiên tiến trong và ngoài nước, các ý kiến phản hồi từ các nhà tuyển dụng và sinh viên tốt nghiệp. Xây dựng và triển khai có hiệu quả các văn bản pháp quy và các chính sách liên quan để định hướng các hoạt động đào tạo theo những quan điểm và phương pháp giáo dục tiên tiến, đáp ứng yêu cầu của học chế tín chỉ.

- Xây dựng và triển khai có hiệu quả hệ thống các văn bản pháp quy và các chính sách liên quan để dịnh hướng các hoạt động NCKH theo các mục tiêu chiến lược của nhà trường, tôn trọng đạo đức trong khoa học và các quy định về sở hữu trí tuệ.

- Các thông tin về đào tạo và $\mathrm{NCKH}$ trên trang web của trường thường xuyên được cập nhật, đảm bảo nhu cầu được thông tin đầy đủ và kịp thời của người học và các bên liên quan.

- Khuyến khích, tạo điều kiện để duy trì và phát triển các hoạt động hợp tác, chia sẻ kinh nghiệm trong đào tạo và $\mathrm{NCKH}$ tại mỗi đơn vị và các đơn vị với nhau trong nhà trường và các cơ sở bên ngoài. 
- Đội ngũ giảng viên có ý thức và nỗ lực học tập để nâng cao trình độ và năng lực chuyên môn, ngoại ngữ, tâm huyết với nghề và giữ gìn đạo đức nhà giáo.

\subsubsection{Phát triển môi truờng xã hội}

- Chức năng, trách nhiệm và quyền hạn của các bộ phận, cán bộ quản lý, giảng viên và nhân viên được phân định rõ ràng và có cơ chế đánh giá chất lượng công việc.

- Hệ thống văn bản để tổ chức, quản lý nhà trường được cập nhật hàng năm, được quy trình hóa và có các hướng dẫn thực hiện cần thiết, được đăng tải đầy đủ trên trang web của nhà trường.

- Các thành viên trong nhà trường hiểu biết đầy đủ trách nhiệm và quyền hạn của mình, có ý thức và nỗ lực hoàn thành nhiệm vụ được giao đúng kế hoạch và có chất lượng.

\subsubsection{Phát triển môi trường nhân văn}

- Nhà trường tạo điều kiện tốt nhất để phát huy đầy đủ các quyền dân chủ và thực hiện đầy đủ các quyền lợi cơ bản theo chế độ chính sách của nhà nước đối với đội ngũ công chức, viên chức và người lao động, người học.

- Xây dựng và triển khai có hiệu quả các cơ chế, chính sách và giải pháp để đội ngũ công chức, viên chức và người lao động, người học thực hiện đầy đủ, chất lượng và hiệu quả trách nhiệm đối với nhà trường và xã hội.

- Tăng cường tinh thần đoàn kết tương thân, tương ái trong mỗi đơn vị, với xã hội và cộng đồng.

- Người học được xem là đối tượng được phục vụ chính trong nhà trường, được quan tâm chăm sóc tận tình, chu đáo trong học tập, sinh hoạt và khi giải quyết công việc.

\subsubsection{Phát triển môi trường văn hóa}

- Xây dựng và triển khai có hiệu quả các giá trị, quy tắc ứng xử, hợp tác, hỗ trợ, tôn trọng lẫn nhau giữa các thành viên, đơn vị, các quy định về nếp sống văn minh nơi công sở.

- Quan tâm phát triển ý thức tự giác ở mỗi cá nhân trong giảng dạy, làm việc, sinh hoạt, học tập, trong thực hiện nếp sống lành mạnh, phát huy truyền thống tốt đẹp của nhà trường và bản sắc văn hóa dân tộc. Xây dựng đời sống văn hóa, văn nghệ, thể dục thể thao cho tất cả cán bộ, viên chức, có ý thức và nỗ lực giữ gìn, phát huy những giá trị tốt đẹp của tập thể, thực hiện nếp sống văn minh, đảm bảo an toàn, an ninh, trật tự trong khuôn viên nhà trường.

\subsubsection{Phát triển môi trường tự nhiên}

- Thư viện của nhà trường có đầy đủ sách, giáo trình, tài liệu tham khảo tiếng Việt và tiếng nước ngoài đáp ứng yêu cầu sử dụng của cán bộ, giảng viên và người học. Có thư viện điện tử được nối mạng phục vụ dạy, học và nghiên cứu khoa học có hiệu quả.

- Cơ sở vật chất, trang thiết bị phục vụ dạy và học, nghiên cứu được đảm bảo về số lượng, chất lượng và được sử dụng có hiệu quả, đáp ứng yêu cầu của các ngành đào tạo.

- Cơ sở vật chất phục vụ ăn, ở, vui chơi sinh hoạt đảm bảo nhu cầu thiết yếu của các thành viên trong nhà trường và ngày càng được nâng cấp, mở rộng.

\subsection{Phát triển hệ thống đảm bảo chất lựng bên trong truò̀ng Đại học Tân Trào}

Với quan điểm chất lượng là sự hài lòng của các bên liên quan và đáp ứng yêu cầu đào tạo nguồn nhân lực cho xã hội, trường Đại học Tân Trào đã xác định đảm bảo chất lượng là yếu tố cốt lõi để thực hiện sứ mạng. Trong nhiều năm qua, nhà trường đã nỗ lực xây dựng hệ thống đảm bảo chất lượng chặt chẽ, các hoạt động được triển khai đến các đơn vị một cách đồng bộ. Việc xây dựng hệ thống tổ chức đảm bảo chất lượng bên trong của trường Đại học Tân Trào được đánh dấu bằng việc thành lập bộ phận kiểm định chất lượng trực thuộc phòng Khảo thí - Đảm bảo chất lượng, với đội ngũ cán bộ chuyên trách nhằm tham mưu, giúp việc, thực thi và trợ giúp cho Hiệu trưởng trong công tác đảm bảo chất lượng của nhà trường. Bên cạnh đó công tác đảm bảo chất lượng được triển khai đồng bộ tới tất cả các đơn vị trong nhà trường, các nhóm chuyên trách được thành lập làm đầu mối triển khai và thực hiện công tác tự đánh giá, kiểm định chất lượng.

Song song với quá trình xây dựng tổ chức các cấp, đội ngũ làm công tác đảm bảo chất lượng được xây dựng. Nhà trường đã cử cán bộ đi bồi dưỡng chuyên môn, nghiệp vụ qua các đợt tập huấn hay hội nghị, hội thảo do Cục Quản lý chất lượng tổ chức. Cán bộ chuyên trách và kiêm nhiệm công tác đảm bảo chất lượng đã có đủ năng lực để đáp ứng yêu cầu tối thiểu của hoạt động đảm bảo chất lượng cấp trường. Các công cụ đánh giá sinh viên tốt nghiệp, sinh viên đánh giá giảng viên, sinh viên đánh giá chương trình môn học đang được sử dụng trong trường, việc ứng dụng công nghệ thông tin trong khảo sát đánh giá đang được triển khai có hiệu quả. Trường Đại học Tân Trào xây dựng, chuẩn hóa hệ thống đảm bảo chất lượng bên trong (IQA) theo định hướng tiêu chuẩn đảm bảo chất 
lượng của mạng lưới các trường đại học Đông Nam Á (AUN-QA) nhằm nâng cao chất lượng và hướng đến hội nhập khu vực.

Hệ thống đảm bảo chất lượng bên trong của trường Đại học Tân Trào được xây dựng theo mô hình của AUN-QA bao gồm các quy trình sau:

- Khuôn mẫu đảm bảo chất lượng nội bộ;

- Các công cụ theo dõi, kiểm tra;

- Các công cụ đánh giá;

- Quy trình đảm bảo chất lượng chuyên biệt cho các hoạt động cụ thể;

- Theo dõi các hoạt động để thực hiện cải tiến.

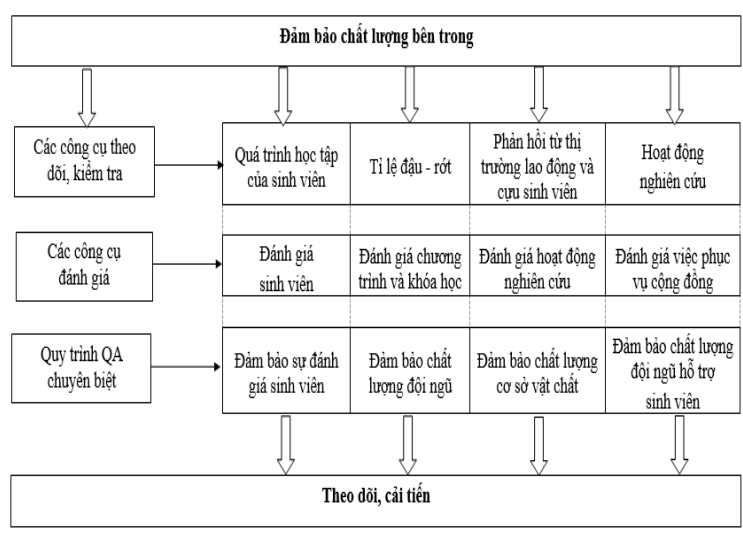

Hình 2: Mô hình đảm bảo chất luợng của trương đại họ Tân Trào

Các quy trình đánh giá đều là các quy trình cốt lõi của hệ thống. Song song với quá trình xây dựng là chuẩn hóa, để phát triển hệ thống đảm bảo chất lượng bên trong, trường Đại học Tân Trào đã xây dựng các chương trình hành động cụ thể để thực hiện tốt các quy trình đảm bảo chất lượng theo các giai đoạn:

* Giai đoạn 1: Triển khai các công cụ theo dõi, kiểm tra việc thu thập thông tin về: Quá trình học tập của sinh viên (sự tiến bộ của sinh viên trong quá trình học tập, số tín chỉ tích lũy, điểm trung bình tích lũy sau mỗi học kỳ...); Tỷ lệ tốt nghiệp đúng hạn (theo dõi, phân tích và đánh giá sự biến động tăng hoặc giảm tỷ lệ sinh viên tốt nghiệp đúng hạn cho mỗi khóa học); Tỷ lệ bỏ học sau mỗi năm ứng với mỗi khóa học; Phản hồi của nhà tuyển dụng và cựu sinh viên (thu thập ý kiến phản hồi từ các bên liên quan một cách xác thực, với số lượng khảo sát đủ lớn, phù hợp và đa dạng để các ý kiến mang tính đại diện cao); Kết quả nghiên cứu khoa học (thống kê và đánh giá hàng năm số lượng công trình nghiên cứu khoa học, các bài báo đăng tải trên các tạp chí khoa học hoặc hội nghị khoa học, số lượng trích dẫn từ các công trình khoa học...của giảng viên và người học).

- Triển khai hệ thống các công cụ đánh giá thông tin về người học: Thu thập ý kiến đánh giá từ sinh viên về chương trình đào tạo, giảng viên phụ trách học phần, cán bộ/nhân viên hỗ trợ...ở cả cấp trường, cấp khoa, bộ môn, thông tin này giúp điều chỉnh các hoạt động đào tạo và đáp ứng yêu cầu người học. Đồng thời thu thập các ý kiến phản hồi về chương trình đào tạo từ giảng viên, nhà tuyển dụng và cựu sinh viên. Triển khai hệ thống đánh giá hoạt động nghiên cứu khoa học.

* Giai đoạn 2: Xây dựng các quy trình và công cụ đảm bảo chất lượng chuyên biệt: Xây dựng những quy định, quy trình liên quan đến các hoạt động bên trong đơn vị nhằm duy trì đều đặn, thường xuyên của công tác đảm bảo chất lượng như: đánh giá sinh viên, đội ngũ giảng viên, đội ngũ hỗ trợ, cơ sở vật chất, hỗ trợ sinh viên... Xây dựng công tác đảm bảo chất lượng theo tiêu chuẩn ISO 9000. Sau một chu kỳ hoạt động sẽ áp dụng phân tích SWOT nhằm xác định những điểm mạnh, điểm yếu, cơ hội và thách thức của đơn vị để có những kế hoạch điều chỉnh cho các chu kỳ tiếp theo. Xây dựng bộ phận kiểm toán nội bộ cấp khoa, cấp trường để tiến hành kiểm quá trình tự đánh giá nhằm kiểm soát các mục tiêu đề ra; Biên soạn sổ tay đảm bảo chất lượng theo các tiêu chuẩn AUN.

* Giai đoạn 3: Triển khai tự đánh giá: Xây dựng kế hoạch triển khai tự đánh giá, xây dựng các công cụ khảo sát, thu thập minh chứng cho các tiêu chí, sắp xếp và lưu trữ minh chứng theo các tiêu chí, viết báo cáo tự đánh giá, tổ chức đánh giá trong nội bộ (thí điểm kiểm định chất lượng đối với một số đơn vị trong nhà trường).

Ngoài ra, trường Đại học Tân Trào tăng cường bồi dưỡng chuyên môn nghiệp vụ cho đội ngũ làm công tác đảm bảo chất lượng tại các chương trình hội thảo, tập huấn và đào tạo ngắn hạn, ưu tiên tham gia các khóa học của AUN-QA về quy trình đảm bảo chất lượng. Mời các chuyên gia đảm bảo chất lượng trong và ngoài nước tập huấn cho toàn bộ cán bộ, giảng viên, chuyên viên trong toàn trường về các kỹ thuật xây dựng công cụ khảo sát, thu thập minh chứng và đưa vào đổi mới chương trình đào tạo. Tăng cường cơ sở vật chất và tài chính phục vụ công tác đảm bảo chất lượng bên trong: Đồng bộ hóa hệ thống công nghệ thông tin trong trường thông qua trang cơ sở dữ liệu đện tử để chia sẻ tài nguyên cũng như các chương trình điều tra khảo sát; đầu tư các module 
khảo sát, đánh giá công tác đảm bảo chất lượng bên trong tại các đơn vị; ưu tiên đầu tư cơ sở vật chất và tài chính cho các đơn vị tham gia công tác đảm bảo chất lượng, chi kinh phí hàng năm cho công tác đảm bảo chất lượng.

\section{Kết luận}

Phát triển văn hóa chất lượng và hệ thống đảm bảo chất lượng bên trong là một yêu cầu cấp thiết và không thể thiếu trong sự tồn tại và phát triển bền vững của cơ sở giáo dục đại học nói chung và trường Đại học Tân Trào nói riêng. Đó cũng là điều kiện quan trọng để nâng cao chất lượng đào tạo. Để tạo dựng và phát triển được văn hóa chất lượng cần xây dựng và vận hành tốt hệ thống đảm bảo chất lượng bên trong. Mặt khác, chỉ khi văn hóa chất lượng trở thành giá trị thường trực trong mọi suy nghĩ, hành động của mọi thành viên trong trường thì hệ thống đảm bảo chất lượng bên trong trường mới có thể phát triển một cách bền vững và chất lượng giáo dục của trường mới có thể được đảm bảo và không ngừng cải tiến. Trường Đại học Tân Trào thực hiện tốt công tác đảm bảo chất lượng để chuẩn bị cho công tác đánh giá ngoài theo quy trình và chu kỳ kiểm định chất lượng giáo dục đại học vào năm 2019, đảm bảo đạt tiêu chuẩn phân tầng cơ sở giáo dục đại học định hướng thực hành và đạt chuẩn quốc gia vào năm 2022.

\section{TÀI LIỆ THAM KHẢO}

1. Vũ Thị Phương Anh, Nhũng thách thức trong việc xây dụng văn hóa chất lương trong các truờng đại học Việt Nam, 2011;
2. Nguyễn Duy Mộng Hà, Xây dụng văn hóa chất luợng theo mô hình quản lý chất luợng tổng thể trong giáo dục đại học, Tạp chí Quản lý giáo dục, số 20, 2011;

3. Lê Văn Hảo, Xây dụng hệ thống đảm bảo chất luợng bên trong và văn hóa chất luợng tại truờng Đại học $K H X H \& N V$, ĐHQG-HCM, Một số quan sát và đề xuất, 2012;

4. Nguyễn Phương Nga, Gắn kết giũa đảm bảo chất lương và văn hóa chất lượng trongtruòng Đại học, Báo cáo tại Hội thảo đảm bảo chất lượng tại Trường Đại học Cần Thơ, ngày 14-17/10/2011;

5. Lê Đức Ngọc, Xây dựng văn hóa chất lương tạo nội lục cho co sở đào tạo đáp úng yêu cầu của thời đại chất lượng, Tạp chí Thông tin khoa học giáo dục, số 36, tháng 4/2008;

6. Richard Lewis, Quality Culture - Basic Concepts, Hội thảo "Xây dụng hệ thống đảm bảo chất lương bên trong và văn hóa chất luợng truờng đại học”, Cục Khảo thí và Kiểm định chất lượng giáo dục, Vinh, ngày 22-24/2/2012;

7. Extenal quality assurance: Options For higher education managers, International Institute For Education Planning, 2006;

8. EUA, Quality Culture in European Universies: A Bottom-up Approach, Report on the three rounds of Quaility Culture Projeet, European University Asociation, Belgium, 2006.

\section{Developing quality culture and the inner quality assurance system at Tan Trao University}

Tran Minh Tu

\section{Article info}

Recieved:

26/01/2018

Accepted:

$10 / 3 / 2018$

Keywords:

Quality culture; quality assurance; heightening education quality.

\begin{abstract}
Developing quality culture and standardizing the inner quality assurance system is an indispensable requirement in the development strategy of Tan Trao University. The inner quality assurance system plays an important role in heightening training quality, scientific research and community services. Promoting quality assurance activities is a crucial duty of the university to meet the demand of human resources in the time development of the society and region, in accordance with the time indispensable trend - internationalization, globalization of Viet Nam education at university level.
\end{abstract}

